\title{
Concerning Elusive Crystal Forms: the case of paracetamol
}

\author{
Yumin Liu, ${ }^{1,2}$ Benjamin Gabriele, ${ }^{2}$ Roger J. Davey, ${ }^{* 2}$ Aurora J. Cruz-Cabeza, ${ }^{* 2}$ \\ ${ }^{1}$ School of Chemical Engineering and Technology, Collaborative Innovation Center of Chemical Science and \\ Chemical Engineering, Tianjin University, Tianjin 300072, P. R. China \\ ${ }^{2}$ School of Chemical Engineering and Analytical Science, University of Manchester, Manchester M13 9PL, \\ United Kingdom
}

\section{S1. Experimental methods}

\section{S1.1 Solubility Measurements}

Form I The solubility of paracetamol form I in IPA at various concentrations of metacetamol were measured at $20{ }^{\circ} \mathrm{C}$ using a gravimetric method. Saturated solutions with excess of form I paracetamol were prepared in double-jacketed glass vessels. The contents of additive relative to the total mass of dissolved paracetamol were $4.95 \mathrm{wt} \%, 12.18 \mathrm{wt} \%$ and $23.90 \mathrm{wt} \%$. Solution temperature was kept by a thermostatic bath (Huber Ministat 230, USA) at $20{ }^{\circ} \mathrm{C}$ with an uncertainty of $\pm 0.01{ }^{\circ} \mathrm{C}$. The solution was stirred continuously for roughly $24 \mathrm{~h}$ by an electric magnetic stirrer to ensure that the solid-liquid equilibrium was reached. The suspension was then settled for $2 \mathrm{~h}$ until most solids had decanted. About $5 \mathrm{~mL}$ of the upper clear saturated solution was taken out using a disposable syringe and filtered $(0.22 \mu \mathrm{m}$ PES filter) into a pre-weighed vial. The vial with saturated solution was weighed by an analytical balance (HM-202, A\&D Company, Limited) with a precision of $\pm 0.0001 \mathrm{~g}$. The vials were then left in the fume cupboard to allow for the solvent to evaporate at room temperature. The mass of the vials was recorded periodically until the total weight of the residue did not change. Each experiment was repeated at least five times and the mean values were used as well as the standard deviations.

Form II The solubility of paracetamol form II in IPA cannot be measured directly because it transforms to the stable form I. The solubility for form II here was first estimated using the solubility ratio theory [1], which was estimated based on the reported solubility data of 
paracetamol polymorphs in water [2]. Subsequently the solubility of form II in IPA was adjusted to the meassured experimental growth data of form II. The final solubility determined here was the concentration derived fitting the growth data with a line passing through the origin.

\section{S1.2 Powder of paracetamol form II preparation}

In order to crystallize powder of paracetamol form II, metacetamol was used as an additive in the crystallisation [3]. $2.5204 \mathrm{~g}$ commercial paracetamol and $0.4947 \mathrm{~g}$ metacetamol $(20 \mathrm{wt} \%)$ were dissolved into $10 \mathrm{ml}$ ethanol, heated to $70{ }^{\circ} \mathrm{C}$ to make the powder dissolve completely and then cooled down to $5{ }^{\circ} \mathrm{C}$ at a rate of $1{ }^{\circ} \mathrm{C} / \mathrm{min}$. The solution was filtered as soon as crystals appeared to avoid transformation to form I.

\section{S1.3 Growth of single crystals}

Form I Single crystals of paracetamol form I were grown by slow evaporation at room temperature. A supersaturated solution with $S=1.1$ at $20{ }^{\circ} \mathrm{C}$ was made by completely dissolving $0.5623 \mathrm{~g}$ commercial powder into $40.01 \mathrm{~g}$ water at $40{ }^{\circ} \mathrm{C}$. The clear solution was filtered with a $0.22 \mu \mathrm{m}$ filter (PES membranes) into glass vials sealed by parafilms with several holes punctured in the centre only. All samples were put in the fume hood for several days to allow crystals to crystallize after the evaporation of water.

Form II Single crystals of paracetamol form II were obtained by fast evaporation at room temperature with metacetamol as the tailor-made additive. $1.1256 \mathrm{~g}$ commercial paracetamol and $0.1144 \mathrm{~g}$ metacetamol were completely dissolved into $80.03 \mathrm{~g}$ water at $40{ }^{\circ} \mathrm{C}$. The solution was filtered with a $0.22 \mu \mathrm{m}$ filter (PES membranes) into glass vials. All samples were put in the fume hood to let them cool down to room temperature naturally. Once the samples cooled down, 2-3 mg of seed powder of paracetamol form II was added into the solution. After that, the solution was left to evaporate fast without cover at room temperature. 


\section{S1.5 Growth rate measurements}

\section{S1.5.1 Growth rate measurement for paracetamol polymorphs}

Growth rate measurements were carried out using an in situ growth cell and an inverted microscope (Olympus CKX41) as described previously [4, 5]. It is noted here that before starting the video record, the seed crystals for paracetamol form I were partially dissolved into smaller sizes while seeds for form II were used without any dissolution. Each experiment point was based on a new single crystal seed checked with a polar microscope (Zeiss Axioplan 2). All growth rate measurements with our setup are only on certain crystallographic directions rather than on specific crystal surfaces. The dimensions for both length and width of our seed crystals were plotted as a function of time to derive the growth rate from the linear slope. In the case of paracetamol form II, seeds were cut prior to being put into the cuvette owing to the particularly long needle-like shape. Thus the dimensions of the seed crystal for paracetamol form II started to be measured when the whole morphology was stable.

\section{S2 Results}

\section{S2.1 Identification of paracetamol polymorphs}

The crystalline structure of paracetamol powders were identified by comparing the experimental PXRD patterns with the calculated patterns from the single crystal structures in the CSD: HXACAN04 (form I) and HXACAN21 (form II).

\section{S2.2 Face indexing for paracetamol polymorphs}

Figure S1 presents the experimental morphology with their indexed faces for the two forms of paracetamol. It is evident that form I grows into block morphology with length and width corresponding to $a$-axis and $\{011\}$ faces respectively while form II grows as needles with length and width corresponding to $a$-axis and $\{012\}$ faces respectively. The unit cell parameters for the experimental seeds and crystal structures extracted from the CSD are given in Table $\mathrm{S} 1$. 

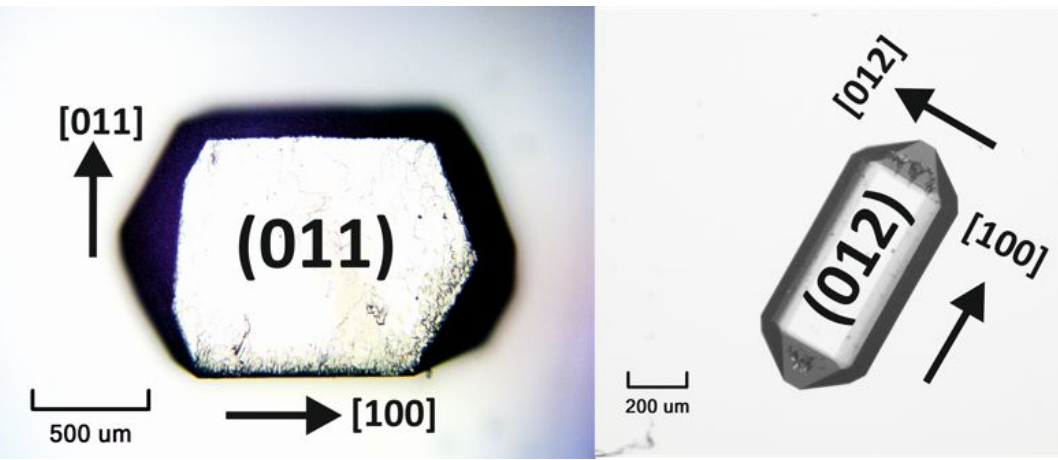

Figure S1 Crystallographic faces on experimental morphology of paracetamol polymorphs: form I (left); form II (right).

Table S1. Space group and unit cell parameters used for indexing forms I and II paracetamol crystals.

\begin{tabular}{lllllllll}
\hline Polymorphs & & $\begin{array}{l}\text { Space } \\
\text { Group }\end{array}$ & $\boldsymbol{a} / \boldsymbol{\AA}$ & $\boldsymbol{b} / \AA$ & $\boldsymbol{c} / \boldsymbol{\AA}$ & $\boldsymbol{\alpha} /{ }^{\circ}$ & $\boldsymbol{\beta} /{ }^{\circ}$ & $\boldsymbol{\gamma} /{ }^{\circ}$ \\
\hline \multirow{2}{*}{ Form I } & HXACA04 & P 21/n & 7.0939 & 9.2625 & 11.6570 & 90.0 & 97.7 & 90.0 \\
& Exp & & 7.0977 & 9.2611 & 11.6331 & 90.0 & 97.9 & 90.0 \\
\multirow{2}{*}{ Form II } & HXACAN21 & Pcab & 7.1986 & 11.7820 & 17.1830 & 90.0 & 90.0 & 90.0 \\
& Exp & & 7.4147 & 11.8501 & 17.2230 & 90.0 & 90.0 & 90.0 \\
\hline
\end{tabular}

\section{S2.3 Additive effects on solubility of paracetamol form I}

The solubilities of paracetamol polymorphs in water and IPA are presented in Table S2 and Figure S2. Overall it is clear that with increasing content of metacetamol the solubility of paracetamol form I increases, thus the supersaturation of the solution will be changed as a function of additive concentration. The calculated supersaturations in the main paper are corrected for this effect.

Table S2. Solubility of paracetamol polymorphs in $\mathrm{g}$ of PCM $/ \mathrm{kg}$ of Solvent.

\begin{tabular}{lll}
\hline Solvent & Form I & Form II \\
\hline Pure Water & $13.22 \pm 0.41$ & 17.30 \\
& $12.78 \pm 0.05^{[6]}$ & \\
Pure IPA & $110.03 \pm 0.31$ & 137.33 \\
& $108.78 \pm 0.30^{[6]}$ & \\
IPA with $4.95 \% \mathrm{MCM}$ & $109.88 \pm 0.13$ & - \\
IPA with $12.18 \% \mathrm{MCM}$ & $111.61 \pm 0.46$ & - \\
IPA with $12.21 \% \mathrm{MCM}$ & $111.47 \pm 0.089$ & - \\
IPA with $23.87 \% \mathrm{MCM}$ & $113.97 \pm 0.42$ & - \\
IPA with $23.90 \% \mathrm{MCM}$ & $113.82 \pm 0.43$ & - \\
\hline
\end{tabular}




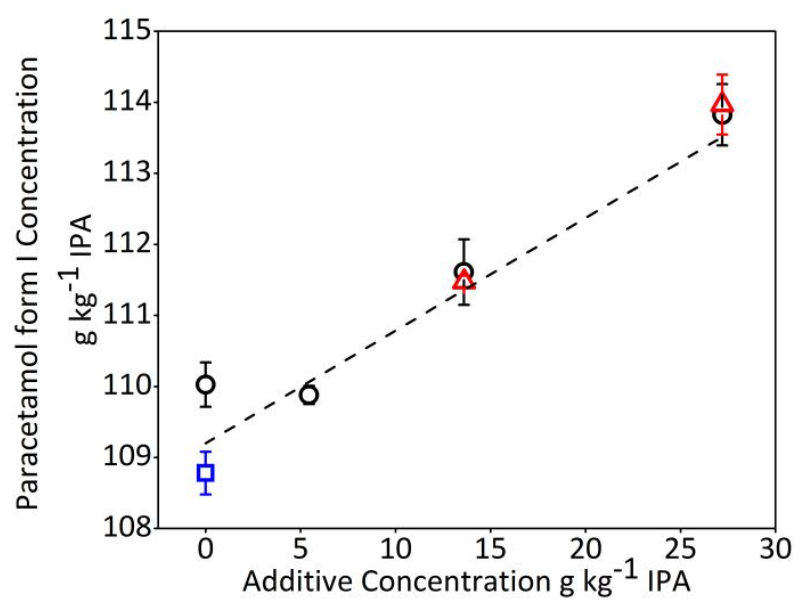

Figure S2 Solubility of paracetamol form I in pure IPA and impure IPA with different concentration of metacetamol at $20^{\circ} \mathrm{C}(\circ \Delta$ gravimetrically measured; $\square$ ref [6])

\section{S2.4 Metacetamol effect on the Crystal Morphologies}

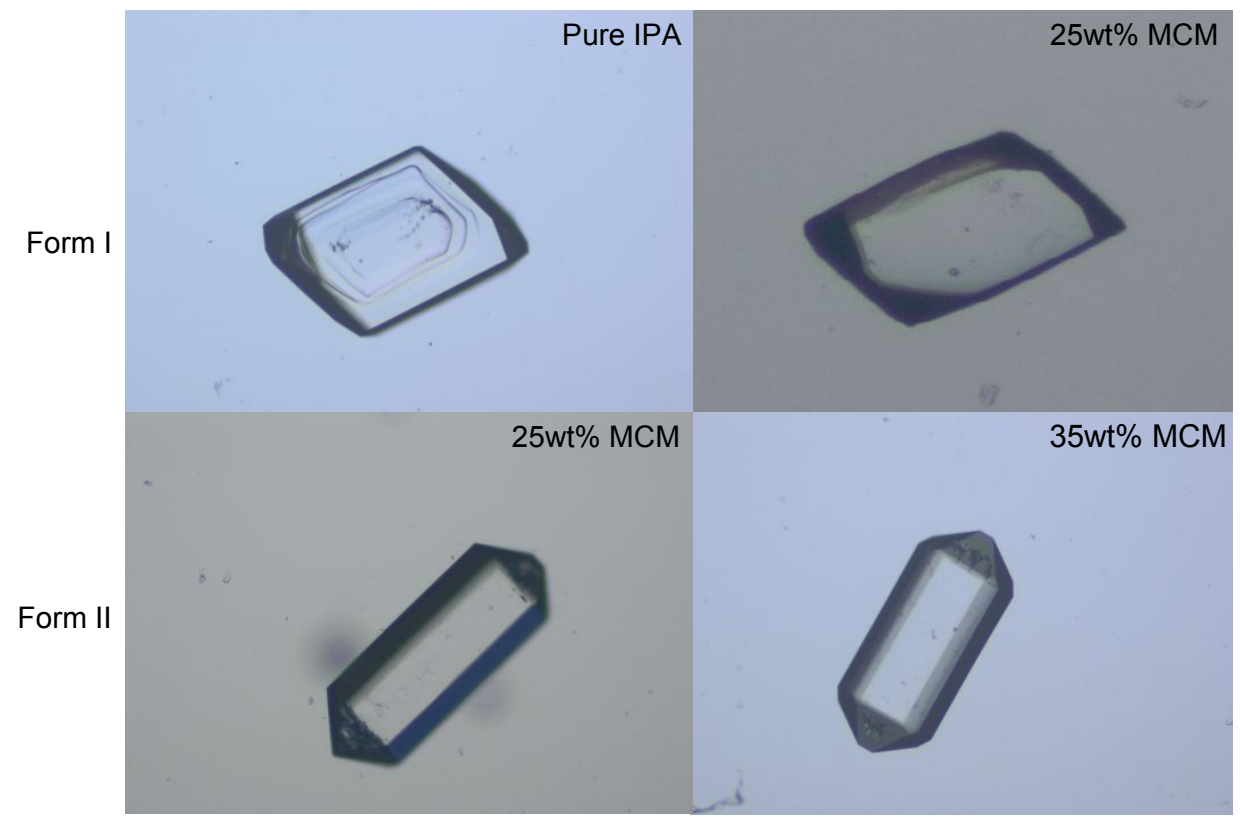

Figure S3 Additive effect on the crystal morphologies of PCM form I (upper) and form II (lower).

\section{S2.5 Crystal growth measurement}

Growth rate measurements for paracetamol form I and form II in IPA solutions with various concentrations of metacetamol were carried out using the growth cell. Figure S3 shows a seed crystal of form I growth in IPA as a function of time. Measurement of the seed dimensions as a function of time (Figure S4) followed by a linear fitting affords the growth rates. Such 
procedure was repeated for the many conditions presented in the main article.

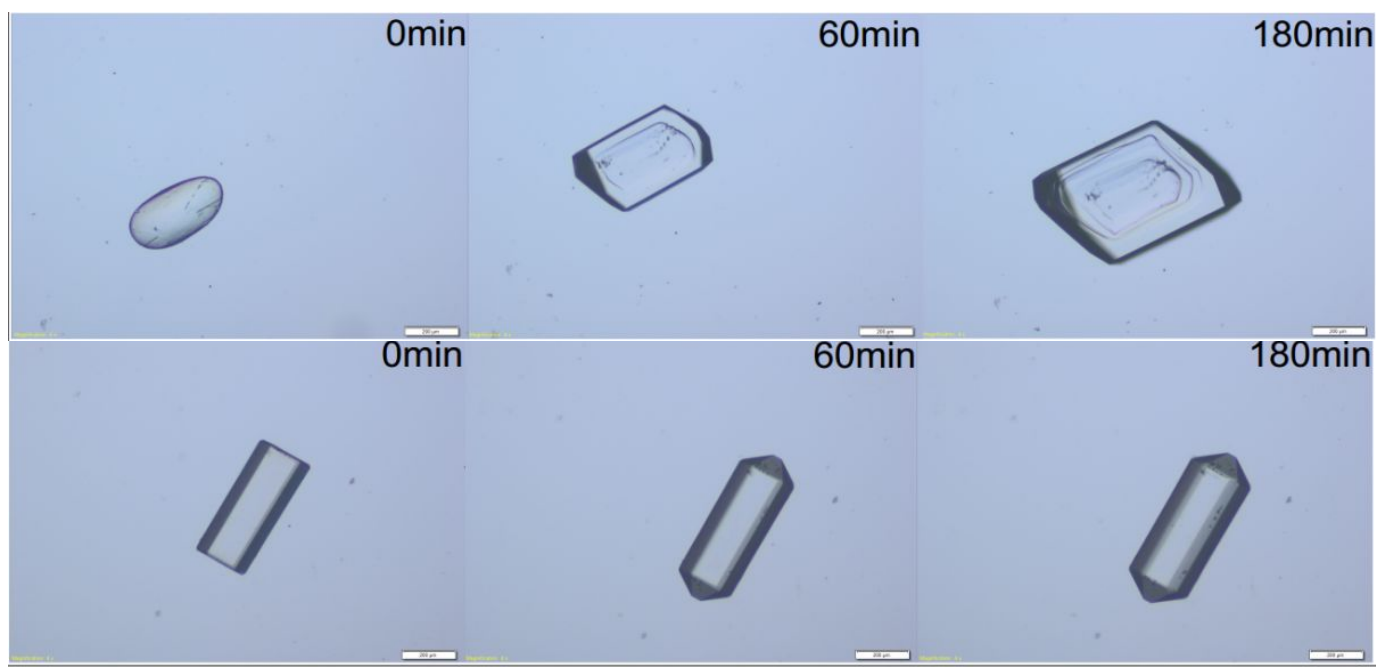

Figure S4. Photomicrographs of seeds of: (upper) paracetamol form I at $S=1.50$ after growth at time 0 $\mathrm{min}, 60 \mathrm{~min}$ and $180 \mathrm{~min}$ in pure IPA at $20 \mathrm{C}$ and (lower) paracetamol form II at $S=1.29$ after growth at time $0 \mathrm{~min}, 60 \mathrm{~min}$ and $180 \mathrm{~min}$ in IPA with $25 \mathrm{wt} \%$ of metacetamol at $20 \mathrm{C}$.

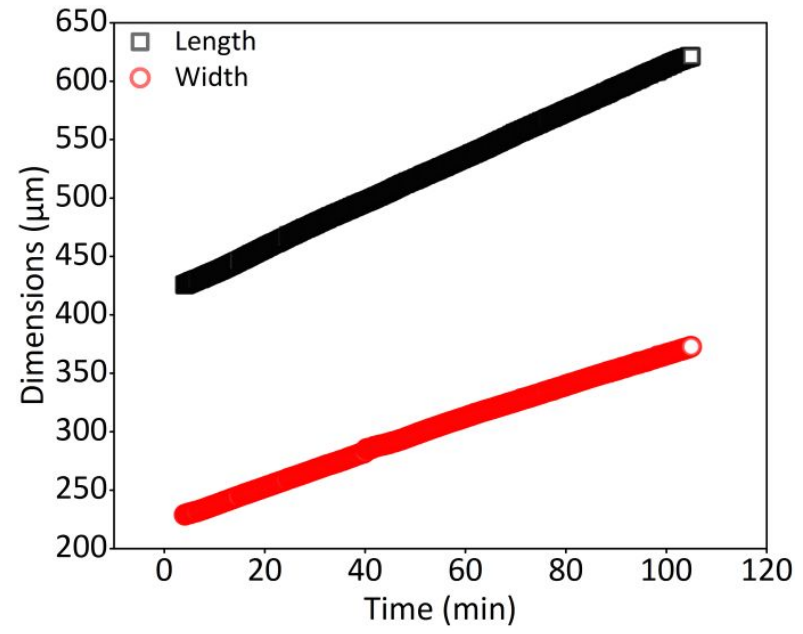

Figure S5. Seed dimension as a function of time for paracetamol form I growing in pure IPA at $S=1.50,20^{\circ} \mathrm{C}$. 


\section{S2.5 Growth Volume Calculations}

Experimental crystal seed dimensions. Table S3 shows a representative set of initial dimensions of the seed crystals after being partially dissolved and before recording crystal growth video.

Table S3. Range of crystal seed dimensions and aspect ratios of crystal seeds used in our growth experiments.

\begin{tabular}{lllll}
\hline Polymorphs & Experimental type & Length $(\boldsymbol{\mu m})$ & Width $(\boldsymbol{\mu m})$ & Aspect ratio $(\mathbf{L} / \mathbf{W})$ \\
\hline \multirow{4}{*}{ Form I } & IPA & $250 \sim 550$ & $110 \sim 300$ & $1 \sim 3$ \\
& IPA+5\%MCM & $150 \sim 300$ & $100 \sim 200$ & $1 \sim 2$ \\
& IPA+12.5\%MCM & $200 \sim 300$ & $130 \sim 250$ & $1 \sim 1.8$ \\
& IPA+25\%MCM & $150 \sim 300$ & $130 \sim 250$ & $1 \sim 1.5$ \\
\multirow{2}{*}{ Form II } & IPA+25\%MCM & $400 \sim 700$ & $230 \sim 450$ & $1 \sim 2$ \\
& IPA+35\%MCM & $200 \sim 550$ & $100 \sim 220$ & $1 \sim 2$ \\
\hline
\end{tabular}

Calculated Growth Volumes. In order to convert the measured linear rates into volumes equation 1 was used. This relates the seed volume at any time $t$ to the size of the initial seed and the measured linear growth rates.

$$
\mathrm{V}[\mathrm{t}, \mathrm{C}]=\left(\mathrm{L}_{0}+\mathrm{R}_{\mathrm{L}}[\mathrm{C}] \mathrm{t}\right)\left(\mathrm{W}_{0}+\mathrm{R}_{\mathrm{W}}[\mathrm{C}] \mathrm{t}\right)\left(\mathrm{T}_{0}+\mathrm{R}_{\mathrm{T}}[\mathrm{C}] \mathrm{t}\right)
$$

where $\mathrm{L}_{0}, \mathrm{~W}_{0}$ and $\mathrm{T}_{0}$ are length, width and thickness of the original crystals at $\mathrm{t}=0$ and $\mathrm{R}_{\mathrm{L}}[\mathrm{C}]$, $\mathrm{R}_{\mathrm{W}}[\mathrm{C}]$ and $\mathrm{R}_{\mathrm{T}}[\mathrm{C}]$ are the growth rates of the length, width and thickness at given concentrations of paracetamol in IPA (C). It is noted that from symmetry considerations that in both forms $\mathrm{R}_{\mathrm{W}}[\mathrm{C}]=\mathrm{R}_{\mathrm{T}}[\mathrm{C}]$.

The growth volume is thus a function of the growth time, original seed dimensions, the growth rates and the solution concentration of PCM. We have chosen to fix the growth time to 60 minutes; this value is arbitrary but in line with our experiments (usually three hours). For the original seed dimensions, based on our experimental ranges, we have adopted initial seed dimensions for bth paracetamol polymorphs of $200 \mu \mathrm{m} \times 100 \mu \mathrm{m} \times 100 \mu \mathrm{m}$. Finally, the rates have simply been taken from the experimental measurements. The results of the calculated volumes for those growth conditions are given in the main article in Figure 4c.

Here, we also explore how different parameter settings influence the volume calculations. In figures S5-S7 we show the impact of the choice of aspect ratio (S6), growth time (S7) and initial seed dimentions (S8). Overall, all data lead to the same conclusions: form I with no 
additive grows faster than form II and form I with additive grows slower than form II.
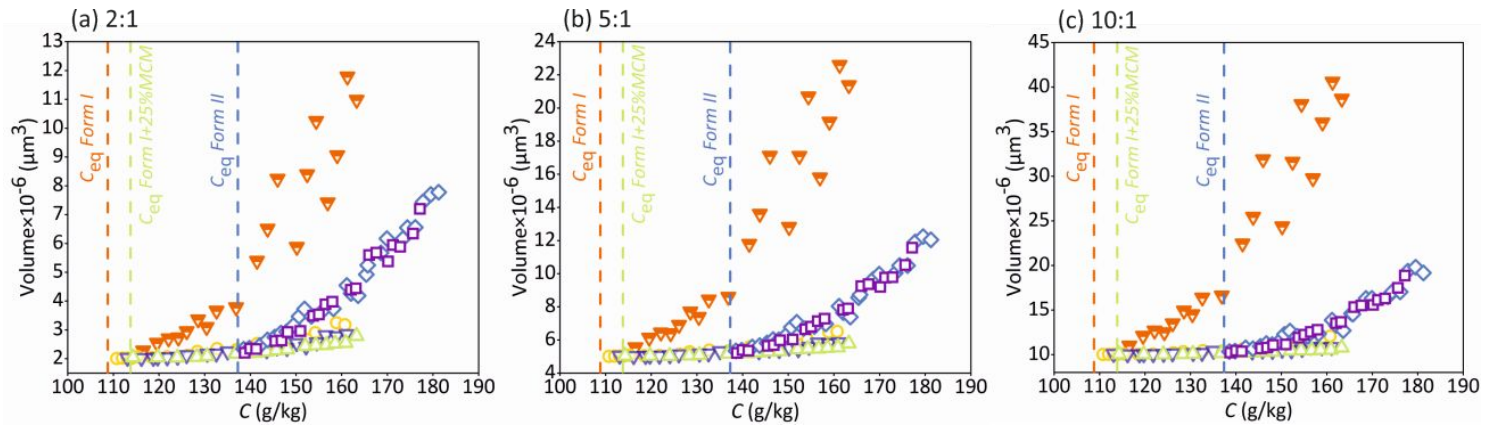

Figure S6. Impact initial seeds aspect ratios $(\mathrm{L} / \mathrm{W}>1)$ on growth volume calculations: $\nabla$ Form I; ${ }_{\text {Form }}$ I $+5 \% \mathrm{MCM} ; \nabla_{\text {Form I }+12.5 \% \mathrm{MCM} ;} \Delta_{\text {Form I }+25 \% \mathrm{MCM}} \diamond_{\text {Form II }+25 \% \mathrm{MCM} ;} \square_{\text {Form II }+35 \% \mathrm{MCM}}$.
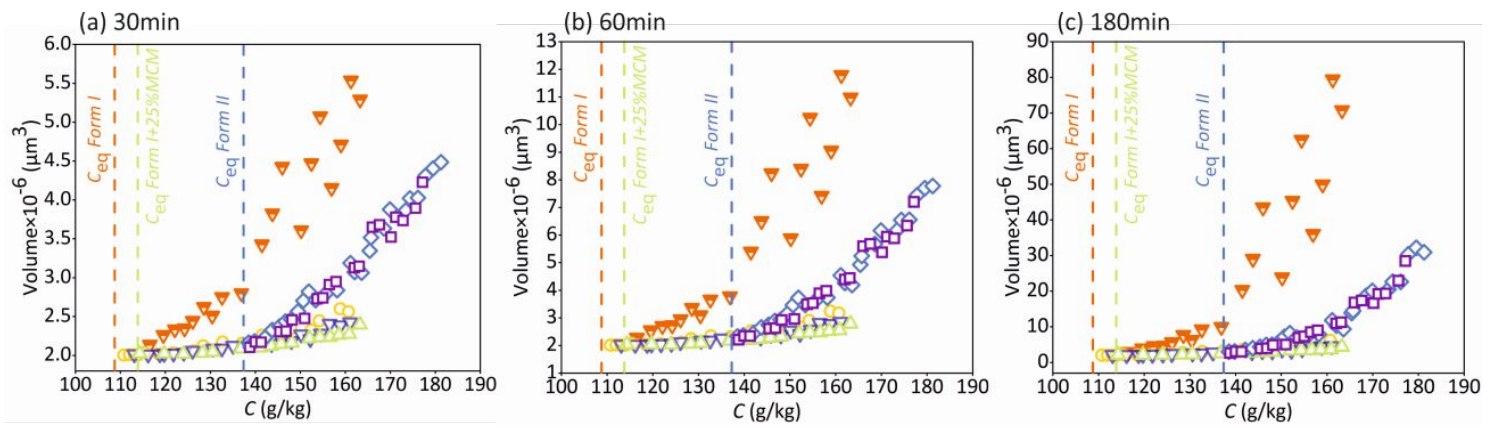

Figure S7. Impact of growth time on growth volume calculations: $\nabla$ Form I; ${ }_{\text {Form I }+5 \% \mathrm{MCM}} \nabla_{\text {Form }}$ $\mathrm{I}+12.5 \% \mathrm{MCM} ; \triangle_{\text {Form I }+25 \% \mathrm{MCM} ;} \diamond_{\text {Form II }+25 \% \mathrm{MCM} ;} \square_{\text {Form II }+35 \% \mathrm{MCM}}$
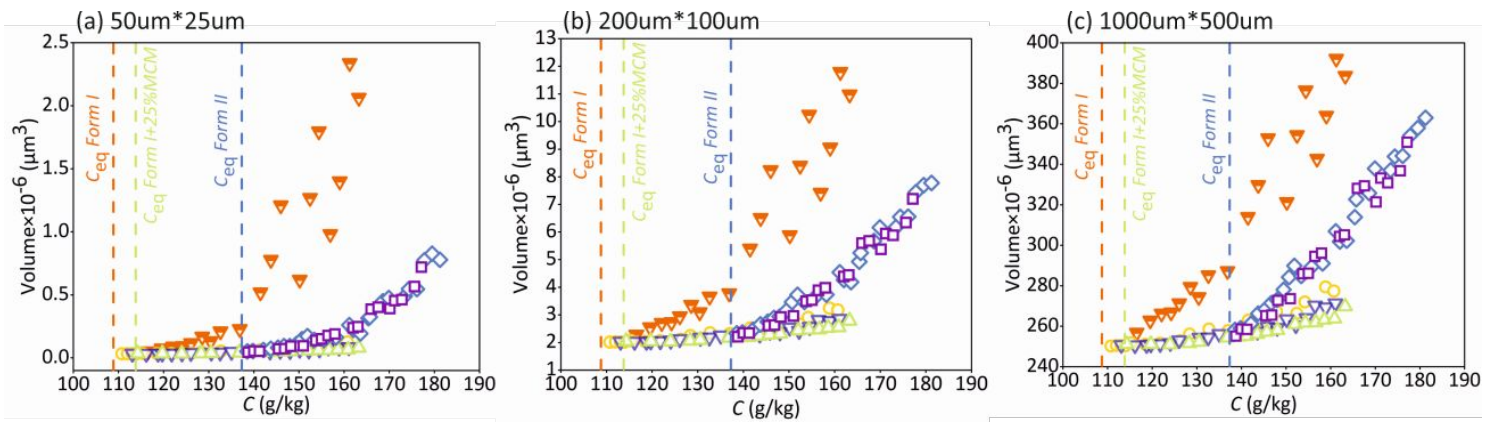

Figure S8. Impact of initial seed dimensions on growth volume calculations: $\nabla$ Form I; ${ }_{\text {Form I+5\%MCM; }}$

$\nabla_{\text {Form I }+12.5 \% \mathrm{MCM} ;} \Delta_{\text {Form I }+25 \% \mathrm{MCM} ;} \diamond_{\text {Form II+25\%MCM; }} \square_{\text {Form II+35\%MCM. }}$ 


\section{References}

(1) Pudipeddi, M.; Serajuddin, A. T. Trends in solubility of polymorphs. J. Pharm. Sci. 2005, 94, 929-939.

(2) Agnew, L. R.; Cruickshank, D. L.; McGlone, T.; Wilson, C. C. Controlled production of the elusive metastable form II of acetaminophen (paracetamol): a fully scalable templating approach in a cooling environment. Chem. Commun. 2016, 52, 7368-7371.

(3) Hendriksen, B. A.; Grant, D. J. The effect of structurally related substances on the nucleation kinetics of paracetamol (acetaminophen). J. Cryst. Growth 1995, 156, 252-260.

(4) Liu, Y.; Black, J.; Boon, K. F.; Cruz-Cabeza, A. J.; Davey, R. J.; Dowling, R.; George, N.; Hutchinson, A.; Montis, R. When crystals don't grow-the growth dead zone. Cryst. Growth Des. 2019, 19, 4579-4587.

(5) Black, J. F.B.; Cardew, P. T.; Cruz-Cabeza, A. J.; Davey, R. J.; Gilks, S. E.; Sullivan, R. A. Crystal nucleation and growth in a polymorphic system: Ostwald's rule, p-aminobenzoic acid and nucleation transition states. CrystEngComm 2018, 20, 768-776.

(6) Granberg, R. A.; Rasmuson, Å.C. Solubility of paracetamol in pure solvents. J. Chem. Eng. Data 1999, 44, 1391-1395.

(7) Hendriksen, B. A.; Grant, D. J.; Meenan, P.; Green, D. A. Crystallisation of paracetamol (acetaminophen) in the presence of structurally related substances. J. Cryst. Growth 1998, 183, 629-640. 